University of Nebraska - Lincoln

DigitalCommons@University of Nebraska - Lincoln

\title{
Earthquake source parameters determined by the SAFOD Pilot Hole seismic array
}

Kazutoshi Imanishi

National Institute of Advanced Industrial Science and Technology

William L. Ellsworth

U.S. Geological Survey

Stephanie G. Prejean

U.S. Geological Survey

Follow this and additional works at: https://digitalcommons.unl.edu/usgsstaffpub

Part of the Earth Sciences Commons

Imanishi, Kazutoshi; Ellsworth, William L.; and Prejean, Stephanie G., "Earthquake source parameters determined by the SAFOD Pilot Hole seismic array" (2004). USGS Staff -- Published Research. 377. https://digitalcommons.unl.edu/usgsstaffpub/377

This Article is brought to you for free and open access by the US Geological Survey at DigitalCommons@University of Nebraska - Lincoln. It has been accepted for inclusion in USGS Staff -- Published Research by an authorized administrator of DigitalCommons@University of Nebraska - Lincoln. 


\title{
Earthquake source parameters determined by the SAFOD Pilot Hole seismic array
}

\author{
Kazutoshi Imanishi, ${ }^{1}$ William L. Ellsworth, ${ }^{2}$ and Stephanie G. Prejean ${ }^{2,3}$ \\ Received 6 January 2004; revised 13 March 2004; accepted 19 March 2004; published 19 May 2004.
}

[1] We estimate the source parameters of \#3 microearthquakes by jointly analyzing seismograms recorded by the 32-level, 3-component seismic array installed in the SAFOD Pilot Hole. We applied an inversion procedure to estimate spectral parameters for the omega-square model (spectral level and corner frequency) and $Q$ to displacement amplitude spectra. Because we expect spectral parameters and $Q$ to vary slowly with depth in the well, we impose a smoothness constraint on those parameters as a function of depth using a linear first-difference operator. This method correctly resolves corner frequency and $Q$, which leads to a more accurate estimation of source parameters than can be obtained from single sensors. The stress drop of one example of the SAFOD target repeating earthquake falls in the range of typical tectonic earthquakes. INDEX TERMS: 7203 Seismology: Body wave propagation; 7200 Seismology; 7209 Seismology: Earthquake dynamics and mechanics; 7215 Seismology: Earthquake parameters. Citation: Imanishi, K., W. L. Ellsworth, and S. G. Prejean (2004), Earthquake source parameters determined by the SAFOD Pilot Hole seismic array, Geophys. Res. Lett., 31, L12S09, doi:10.1029/2004GL019420.

\section{Introduction}

[2] Stress drop is a key parameter needed to understand the physics of earthquakes, investigate seismic source scaling relationships, and infer the local stress level in the crust. Many researchers have determined the static stress drops of microearthquakes from corner frequencies of spectra and spectral levels by fitting the $\omega^{2}$-model [e.g., Boatwright, 1978] with attenuation correction $(Q)$ [e.g., Abercrombie, 1995]. However, it is difficult to determine reliable spectral parameters simultaneously, since corner frequency and $Q$ are highly dependent on one another and not well resolved from each other in the spectral fitting. This leads to large uncertainties in the source parameters such as static stress drop.

[3] One approach to overcome this problem is to cancel the attenuation factor by taking the spectral amplitude ratio between spectra of co-located event pairs [e.g., Hough, 1997]. The application of this approach is restricted to the situation where co-located events with similar focal mechanisms are available. Dimensions of the earthquakes used as empirical Green's functions also set the lower limit of earthquake size to which the method might be applied.

\footnotetext{
${ }^{1}$ Geological Survey of Japan, National Institute of Advanced Industrial Science and Technology, Tsukuba, Japan.

${ }^{2}$ U.S. Geological Survey, Menlo Park, California, USA.

${ }^{3}$ USGS Alaska Volcano Observatory, Anchorage, Alaska, USA.
}

Another possible approach is to use stopping phases [e.g., Imanishi and Takeo, 2002]. The advantage is that the differential time between stopping phases is effected by common mode path effects including attenuation. However the approach requires very high frequency data and a network of observation points.

[4] The observation of seismic waves at various depths within a borehole, known as vertical seismic profiles (VSP), became more common in the late 1970s in seismic exploration, and the VSP has been shown a useful tool for the delineation of seismic wave propagation properties near a well [e.g., Hardage, 1985]. Although, in seismology, these data have been mainly used to study near-surface attenuation and site response of seismic waves, they could be also used for reliable source parameter estimations of microearthquakes by jointly analyzing the entire borehole seismic array. In the summer of 2002, the Pilot Hole for the San Andreas Fault Observatory at Depth (SAFOD) was drilled to a depth of $2.2 \mathrm{~km}$. The site is about $1.8 \mathrm{~km}$ southwest of a segment of the San Andreas fault and lies just north of the rupture zone of the M 61966 Parkfield earthquake (Figure 1). The seismic array consists of 32 levels of 3-component geophones at 40 meter spacing (856 to $2096 \mathrm{~m}$ depth). The sensors have a natural frequency of $15 \mathrm{~Hz}$ and damping constant of 0.57 . The data were recorded at a sampling rate of $1 \mathrm{kHz}$ in July 2002 and then increased to $2 \mathrm{kHz}$ in December 2002. A large number of high quality data have been accumulated and important results have been reported [e.g., Chavarria et al., 2003].

[5] The purpose of this study is to develop a technique for estimating source parameters using a borehole seismic array. In order to decrease uncertainties in the source parameter estimates, we apply smoothing constraints that links spectral level, $Q$, and corner frequency at one level to the levels above and below. The method will be applied to a microearthquake (M1.3) recorded at the SAFOD Pilot Hole to demonstrate its effectiveness.

\section{Method of Estimating Source Parameters Using a Borehole Seismic Array}

[6] Following Boatwright [1978], we approximate the logarithm of displacement amplitude spectrum at $i$ th station as

$$
\begin{aligned}
d^{i}= & g^{i}\left(f ; \Omega_{o}^{i}, 1 / Q^{i}, f_{o}^{i}\right)=\log \Omega_{0}^{i}-\log \left[1+\left(f / f_{0}^{i}\right)^{4}\right] / 2 \\
& -\pi f t^{i} \log e\left(1 / Q^{i}\right)+e
\end{aligned}
$$

where $\Omega_{0}^{i}, Q^{i}, f_{0}^{i}$ and $t^{i}$ are spectral level, path-averaged attenuation, corner frequency and travel time at $i$ th location, respectively. $f$ is frequency. $e$ is the error between the observed and synthetic spectrum. The above equation is 


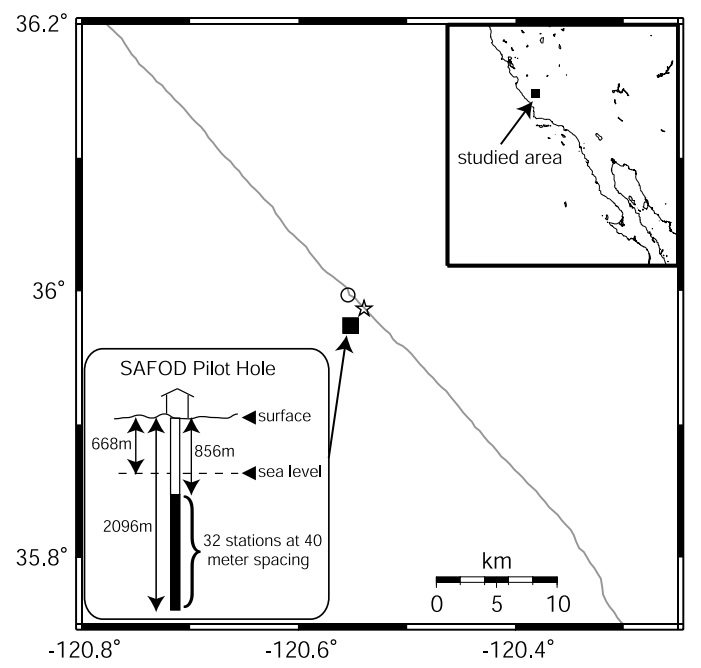

Figure 1. Location of the SAFOD Pilot Hole (square). Circle is an epicenter for the 2311 UT event of December 27, 2002. Star shows the location of SAFOD's repeating magnitude 2.1 target event, which occurred at 1125 UT on 20 October 2003. The gray line shows the surface trace of the San Andreas fault.

linear for $\Omega_{0}^{i}$ and $1 / Q^{i}$ and nonlinear for $f_{0}^{i}$. We can solve it using the Levenberg-Marquart method that minimizes the residual $S=\left\|d^{i}-g^{i}\left(f ; \Omega_{o}^{i}, 1 / Q^{i}, f_{o}^{i}\right)\right\|^{2}$.

[7] An effective approach can be developed when we have borehole seismic array data. We expect spectral levels to vary systematically with depth, because they depend on the hypocentral distance and radiation pattern coefficient. For some of the nearby events, take-off angles to the different levels of the array span a significant part of the focal sphere. Since corner frequencies are a function of take-off angle, they will be slightly dependent on the depth of each instrument. Therefore corner frequencies and spectral levels should change slowly with depth. $Q$ is an effective value for the whole propagation path, so that it should also vary smoothly with position in the borehole. Thus we impose a smoothness constraint on $\Omega_{0}^{i}, 1 / Q^{i}$ and $f_{0}^{i}$ as a function of depth. In order to smooth measurements, we use a linear first-difference operator that links $\Omega_{0}^{i}, 1 / Q^{i}$ and $f_{0}^{i}$ at one level to the levels above and below. Our goal is to minimize the following residual:

$$
\begin{aligned}
S= & \sum_{i=1}^{N_{S}}\left\{\left\|d^{i}-g^{i}\left(f ; \Omega_{o}^{i}, 1 / Q^{i}, f_{o}^{i}\right)\right\|^{2}+\lambda_{1}\left[\Omega_{o}^{i}-\Omega_{o}^{i-1}\right]^{2}\right. \\
& \left.+\lambda_{2}\left[\left(1 / Q^{i}\right)-\left(1 / Q^{i-1}\right)\right]^{2}+\lambda_{3}\left[f_{o}^{i}-f_{o}^{i-1}\right]^{2}\right\}
\end{aligned}
$$

where $N_{S}$ is the number of array. Since we jointly analyze the entire array, the total number of model parameters is $3 N_{S} . \quad \lambda_{1}, \lambda_{2}$ and $\lambda_{3}$ are weights for the smoothing constraints. In order to obtain suitable weights, we use Akaike's Bayesian Information Criterion (ABIC) [Akaike, 1980]. ABIC for our problem is expressed by the following equation:

$$
\begin{aligned}
\mathrm{ABIC}= & \left(N+3 N^{\prime}-3 N_{S}\right) \log \hat{S}-N^{\prime}\left(\log \lambda_{1} \lambda_{2} \lambda_{3}\right) \\
& +\log \left\|\boldsymbol{F}^{\boldsymbol{t}} \boldsymbol{F}+\left(\lambda_{1} \lambda_{2} \lambda_{3}\right) \boldsymbol{D}^{\boldsymbol{t}} \boldsymbol{D}\right\|+\text { const }
\end{aligned}
$$

where $\hat{S}$ is the residual for best estimate of model parameters. $\boldsymbol{F}$ and $\boldsymbol{D}$ are Jacobian matrices, whose components are partial derivatives of $g^{i}\left(f ; \Omega_{o}^{i}, 1 / Q^{i}, f_{o}^{i}\right)$ and the smoothing constraint with respect to the model parameters, respectively. The component of $\boldsymbol{D}$ is expressed by

$$
D_{i j}=\left[\begin{array}{ccccccc}
-1 & 1 & & & & 0 \\
& -1 & 1 & & & \\
& & \cdot & \cdot & & \\
& & & \cdot & \cdot & \\
0 & & & & -1 & 1
\end{array}\right]
$$

$N$ and $N^{\prime}$ are the total number of data points and the rank of $D^{t} D$, respectively.

[8] We compute seismic moment using the relation: $M_{o}=$ $\left[\sum_{i=1}^{N}\left(4 \pi \rho v^{3} R^{i} \Omega_{o}^{i} / F^{i}\right)\right] / N$, where $\rho$ is density $\left(2700 \mathrm{~kg} / \mathrm{m}^{3}\right), v$ is velocity $(5.8 \mathrm{~km} / \mathrm{s}$ and $3.3 \mathrm{~km} / \mathrm{s}$ for $P$ and $S$ waves, respectively). $R^{i}$ and $F^{i}$ are the hypocentral distance and the radiation pattern coefficient at $i$ th station. We determine the source radius $r$ using the circular crack model of Sato and Hirasawa [1973]:

$$
r=\left[\sum_{i=1}^{N}\left(C v / 2 \pi f_{o}^{i}\right)\right] / N,
$$

where $C$ is 1.5 and 1.9 for $P$ and $S$ waves, respectively. The reported $M_{o}$ and $r$ values are the average of $P$ and $S$ waves. The static stress drop is then calculated by the formula of Eshelby [1957]: $\Delta \sigma=(7 / 16)\left(M_{o} / r^{3}\right)$.

\section{Application to the SAFOD Pilot Hole Array}

[9] In the following, we explain in detail the estimation of source parameters for an earthquake that occurred at 2311 UT on 27 December 2002 as an example. The circle in Figure 1 shows the epicenter, with hypocenter being at a depth of $3.32 \mathrm{~km}$ below mean sea level. This event was recorded at sampling rate of $2 \mathrm{kHz}$. Three component seismograms were rotated into $P, S H$ and $S V$ wave directions, maximizing the summation of $P, S H$ and $S V$ wave energies. Figure 2a displays observed velocity seismograms of $P$ component, where we removed noisy seismograms from $1336 \mathrm{~m}, 1496 \mathrm{~m}, 2056 \mathrm{~m}$ and $2096 \mathrm{~m}$ depth. We then calculate the Fourier spectral amplitude for each component. In order to contain body waves and exclude reflected waves from the surface, the length of time windows was set to $0.2 \mathrm{~s}$ for the $P$ wave and $0.4 \mathrm{~s}$ for the $S$ wave. After correcting instrumental response, we resample each spectral amplitude at equal intervals in log frequency at $\Delta \log f=0.025$ and take a moving window average of length $\Delta \log f=0.1$. Those spectra are then corrected for the radiation pattern coefficient. Since almost all events near the Parkfield region have right-lateral strike-slip focal mechanisms [e.g., Eberhart-Phillips and Michael, 1993], we assume (strike, dip, slip) $=\left(140^{\circ}, 90^{\circ}\right.$, $180^{\circ}$ ). In the calculation of take-off angle, we use a velocity model in the southwest side of the fault proposed by Ellsworth [1996]. We calculate $S$ wave amplitude spectra as the vector summation of $S H$ and $S V$ spectra. Noise spectra were also calculated using the presignal record. Figure $2 \mathrm{~b}$ shows displacement spectra at three 


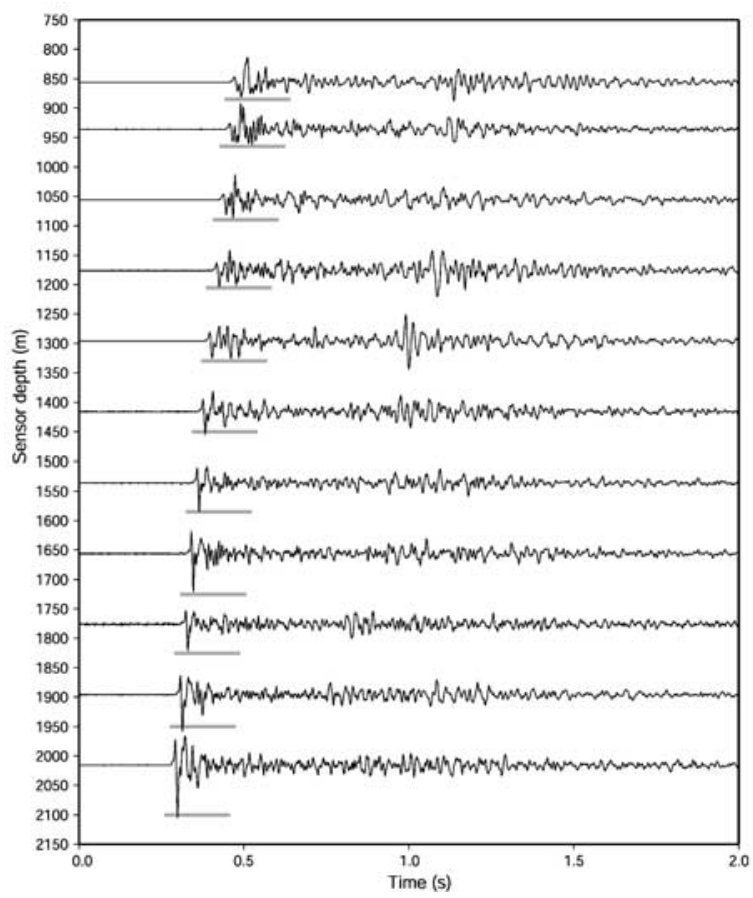

Figure 2a. Observed velocity seismograms of $P$ component for the 2311 UT event of December 27, 2002. Gray bars represent time windows to calculate spectra.

levels of the array. It should be noted that spectra have high signal-to-noise ratios at frequencies up to $300 \mathrm{~Hz}$, indicating these data include information on source processes of microearthquakes.

[10] First, we estimated $\Omega_{0}, Q$ and $f_{o}$ at individual levels of the array by solving (3). The spectral fitting was performed for frequencies between 10 and $300 \mathrm{~Hz}$ where signal to noise ratio was greater than 2. As seen in Figure 3a, $Q$ and $f_{o}$ scatter significantly through the level of the array. Considering earthquake size and hypocentral distance, it is unlikely that $f_{o}$ varies rapidly over short distances. The scatter seems to originate partially in the instability of the simultaneous parameter inversion using a single spectrum. Specifically, $f_{o}$ and $Q$ reshape the spectrum in similar ways, and are therefore difficult to resolve.

[11] To improve resolution of $f_{o}$ and $Q$, we then estimated source parameters imposing a smoothness constraint on $\Omega_{0}$, $Q$ and $f_{o}$ as a function of depth. In Figure $3 \mathrm{~b}$, we show the result with the minimum ABIC. $\Omega_{0}$ and $Q$ vary systematically and $f_{o}$ does not scatter with depth, suggesting that the joint analysis with smoothing constraints overcome the

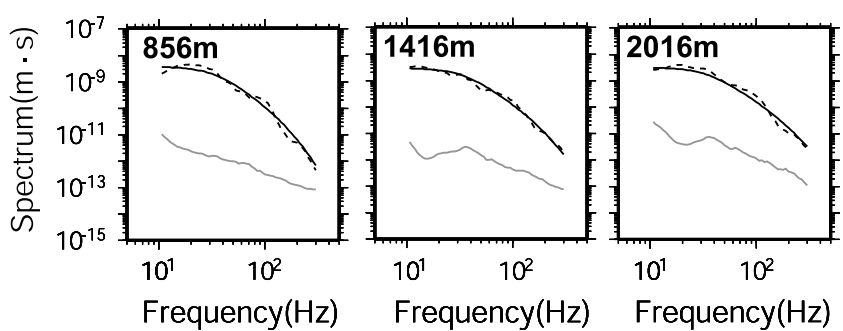

Figure 2b. Displacement amplitude spectra for the event in Figure 2a (dashed lines). Solid lines are fitted $\omega^{2}$-model. Noise spectra are drawn by gray lines.
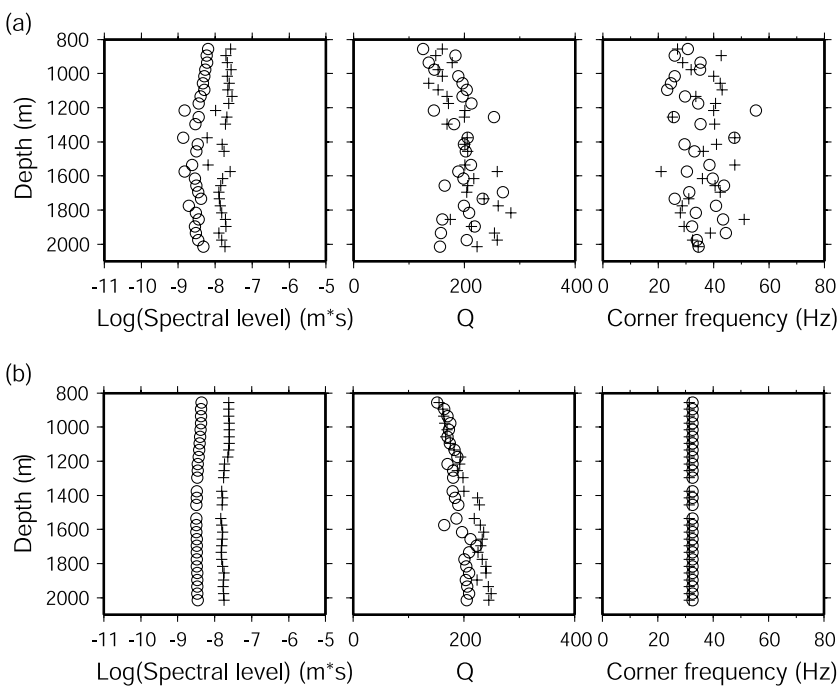

Figure 3. (a) Estimated values of $\Omega_{0}, Q$ and $f_{o}$ at individual level of the array without smoothness constraints. (b) Estimated values of $\Omega_{0}, Q$ and $f_{o}$ at individual level of the array with smoothness constraints. Estimations for $P$ and $S$ waves are shown by circles and pluses, respectively.

problems described above. $Q_{p}$ and $Q_{s}$ change from 150 to 200 and from 150 to 250 with depth, respectively. Abercrombie [2000] determined $Q$ values at Parkfield. Attenuation to the SW of the San Andreas fault was estimated to be about 200 between 200 and $5000 \mathrm{~m}$ depth for both $P$ and $S$ waves. Her result is consistent with that obtained here within the various uncertainties. Seismic moment, source radius and static stress drop were estimated to be $8.3 \times 10^{10} \mathrm{Nm}(\mathbf{M} 1.3), 35.6 \mathrm{~m}$ and $0.8 \mathrm{MPa}$, respectively. Since the static stress drop is a modeldependent parameter, the numerical value depends on the choice of source models. Two rupture models [Brune, 1970; Madariaga, 1976] are often used for determining source parameters of microearthquakes from the spectral parameters of the omega-squared model. The $S$ wave stress drops estimated using the Brune model and the Madariaga model are 0.3 and 1.9 times that obtained using the Sato and Hirasawa model. The value of stress drop, however, is in the range of other studies regardless of the model used [e.g., Abercrombie, 1995; Prejean end Ellsworth, 2001].

\section{Discussion and Conclusions}

[12] In order to confirm the reliability of our estimates, we checked corner frequencies by taking the spectral amplitude ratio between the spectra of the 2311 UT event of December 27, 2002, and colocated smaller event that occurred at 2247 UT on December 27, 2002. Analysis of the 2247 UT event with our approach gave $P$ and $S$ wave corner frequencies of $60 \mathrm{~Hz}$ and $57 \mathrm{~Hz}$, respectively. A spectral ratio for both events was calculated from the logarithmic average of spectral ratios at individual level of the array. We determined corner frequencies of the two events by fitting the spectral ratio curve with the $\omega^{2}$-model (equation (1)). The best fitting $P$ and $S$ wave corner frequencies are $35 \mathrm{~Hz}$ and $31 \mathrm{~Hz}$ for larger event and $61 \mathrm{~Hz}$ and $59 \mathrm{~Hz}$ for smaller one, respectively. These values agree well with our estimations, supporting the assertion that we can make reliable 


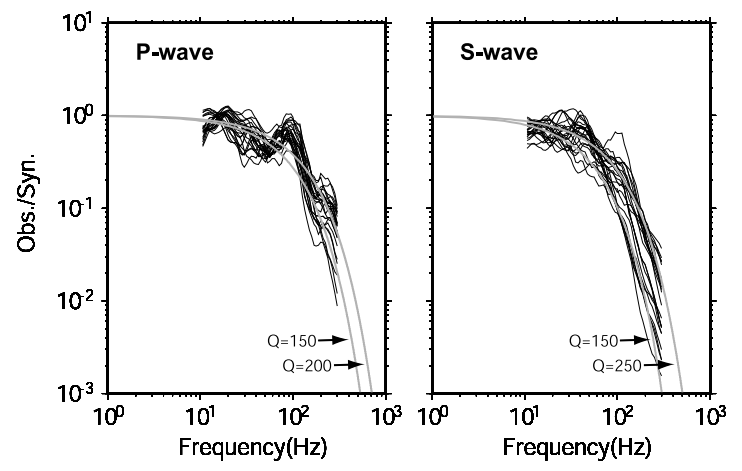

Figure 4. Ratios between observed and synthetic $\omega^{2}$ spectra from $\Omega_{0}$ and $f_{o}$ in Figure $3 \mathrm{~b}$. Gray lines show attenuation curves assuming a frequency independent $Q$ and travel time at the middle of the array.

corner frequency estimates by jointly analyzing the entire borehole array.

[13] In this study, we modeled crustal attenuation with a frequency independent $Q$ operator. However the validity of the frequency independent $Q$ has not been fully confirmed. Abercrombie [1998] compiled several studies of attenuation determined by borehole recordings and found that the attenuation factor increases only weakly with frequency between 10 and $100 \mathrm{~Hz}$. These observations might support a frequency independent $Q$ assumption at higher frequency as a first order approximation. On the other hand, Ide et al. [2003] reported that it would be more appropriate to consider frequency dependent attenuation even in the relatively clean recording environment of a deep borehole. They indicated that the assumption of a frequency independent $Q$ introduces an artificial size dependence in the source scaling relations of stress drop and apparent stress measurements. In order to investigate the frequency dependence of attenuation, we derived attenuation curves $\exp [-\pi f t / Q(f)]$ for $P$ and $S$ waves at each level of the array by taking the ratio between observed $u(f)$ and synthetic spectra $\Omega_{o} /\left[1+\left(f / f_{o}\right)^{4}\right]^{1 / 2}$ (Figure 4). Here, we used $\Omega_{0}$ and $f_{o}$ estimated at each level of the array in the calculation of the synthetic spectra. Except for the strong amplification at around $90 \mathrm{~Hz}$ for the $P$ wave, these curves are well explained by a constant $Q$ model. Although the $90 \mathrm{~Hz}$ amplification of $P$ wave might affect the determination of corner frequency, it seems that the present array approach can suppress the influence of frequency dependent attenuation, when the corner is well separated from the anomalous response.

[14] In Parkfield, California, Nadeau and Johnson [1998] derived the scaling relation for stress drops with seismic moment of repeating earthquakes. The implied stress drops decrease from $\sim 2000 \mathrm{MPa}$ to $100 \mathrm{MPa}$ for $\mathbf{M}$ from $\sim 0$ to 3 . Although their estimates are independent of models of the dynamic rupture process, they are much higher than those calculated from seismic methods using corner frequency or pulse width for comparable-sized events [e.g., Abercrombie, 1995; Prejean and Ellsworth, 2001]. Several models have been proposed to explain the discrepancy [e.g., Beeler et al., 2001]. However, it is not yet clear whether stress drops of small repeating earthquakes are truly high.

[15] A repeating magnitude 2.1 earthquake occurred at 1125 UT on 20 October 2003 (star in Figure 1) at a depth of $\approx 2.2 \mathrm{~km}$ below mean sea level [see Thurber et al., 2004]. This earthquake was a member of the multiplet cluster that SAFOD's drilling program was designed to penetrate. Nadeau et al. [2004] reported that the recurrence interval of the event is consistent with the recurrence interval scaling determined by Nadeau and Johnson [1998]. According to their scaling relation, this event is predicted to have a stress drop of $245 \mathrm{MPa}$. We applied the present approach to the target event and determined source parameters. Moment magnitude and stress drop were estimated to be 2.1 and 8.9 $\mathrm{MPa}$, respectively. Our measurement suggests that some small repeating earthquake at Parkfield have a typical tectonic stress drop. By applying our approach to a borehole array, we believe that the stress drop question at Parkfield can be resolved from an observational point of view.

[16] Acknowledgments. We thank Eylon Shalev and Peter Malin of Duke University for their dedication to the operation of the SAFOD Pilot Hole seismic array and for distributing the data within the research community. Comments by Art McGarr, Paul Spudich, Stephen Hickman, and two anonymous reviewers were helpful in improving the manuscript. Figures have been generated using the Generic Mapping Tool [Wessel and Smith, 1995]. K.I was supported by a Grant-in-Aid for Japan-U.S. Cooperative Science Program of the Japan Society for the Promotion of Science.

\section{References}

Abercrombie, R. E. (1995), Earthquake source scaling relationships from -1 to $5 \mathrm{M}_{\mathrm{L}}$ using seismograms recorded at $2.5-\mathrm{km}$ depth, J. Geophys. Res., 100, 24,015-24,036.

Abercrombie, R. E. (1998), A summary of attenuation measurements from borehole recordings of earthquakes: The $10 \mathrm{~Hz}$ transition problem, Pure Appl. Geophys., 153, 475-487.

Abercrombie, R. E. (2000), Crustal attenuation and site effects at Parkfield, California, J. Geophys. Res., 105, 6277-6286.

Akaike, H. (1980), Likelihood and the Bayes procedure, in Bayesian Statistics, edited by J. M. Bernardo et al., pp. 143-166, Univ. Press, Valencia, Spain.

Beeler, N. M., D. L. Lockner, and S. H. Hickman (2001), A simple stickslip and creep-slip model for repeating earthquakes and its implication for microearthquakes at Parkfield, Bull. Seismol. Soc. Am., 91, 1797-1804.

Boatwright, J. (1978), Detailed spectral analysis of two small New York State earthquakes, Bull. Seismol. Soc. Am., 68, 1117-1131.

Brune, J. N. (1970), Tectonic stress and the spectra of seismic shear waves from earthquakes, J. Geophys. Res., 75, 4997-5009.

Chavarria, J. A., P. Malin, R. D. Catchings, and E. Shalev (2003), A look inside the San Andreas fault at Parkfield through vertical seismic profiling, Science, 302, 1746-1748.

Eberhart-Phillips, D., and A. J. Michael (1993), Three-dimensional velocity structure, seismicity, and fault structure in the Parkfield region, central California, J. Geophys. Res., 98, 15,737-15,758.

Ellsworth, W. L. (1996), Drilling into the earthquake source: The search for a site to test theories of earthquake generation at Parkfield, paper presented at VIII International Symposium on the Observation of the Continental Crust Through Drilling, Natl. Inst. of Adv. Ind. Sci. and Technol., Tsukuba, Japan.

Eshelby, J. D. (1957), The determination of the elastic field of an ellipsoidal inclusion and related problems, Proc. R. Soc. London, Ser. A, 241, 376396.

Hardage, B. A. (1985), Vertical Seismic Profiling-Part A: Principles, 2nd ed., Geophys. Press, London.

Hough, S. E. (1997), Empirical Green's function analysis: Taking the next step, J. Geophys. Res., 102, 5369-5384.

Ide, S., G. C. Beroza, S. G. Prejean, and W. L. Ellsworth (2003), Apparent break in earthquake scaling due to path and site effects on deep borehole recordings, J. Geophys. Res., 108(B5), 2271, doi:10.1029/ 2001JB001617.

Imanishi, K., and M. Takeo (2002), An inversion method to analyze rupture processes of small earthquakes using stopping phases, J. Geophys. Res., 107(B3), 2048, doi:10.1029/2001JB000201.

Madariaga, R. (1976), Dynamics of an expanding circular fault, Bull. Seismol. Soc. Am., 66, 639-666.

Nadeau, R. M., and L. R. Johnson (1998), Seismological studies at Parkfield VI: Moment release rates and estimates of source parameters for small repeating earthquakes, Bull. Seismol. Soc. Am., 88, 790-814. 
Nadeau, R. M., A. Michelini, R. A. Uhrhammer, D. Dolenc, and T. V. McEvilly (2004), Detailed kinematics, structure and recurrence of micro-seismicity in the SAFOD target region, Geophys. Res. Lett., 31, L12S08, doi:10.1029/2003GL019409.

Prejean, S. G., and W. L. Ellsworth (2001), Observations of earthquake source parameters at $2 \mathrm{~km}$ depth in the Long Valley Caldera, eastern California, Bull. Seismol. Soc. Am., 91, 165-177.

Sato, T., and T. Hirasawa (1973), Body wave spectra from propagating shear cracks, J. Phys. Earth, 21, 415-431.

Thurber, C., S. Roecker, H. Zhang, S. Baher, and W. Ellsworth (2004), Finescale structure of the San Andreas fault zone and location of the SAFOD target earthquakes, Geophys. Res. Lett., 31, L12S02, doi:10.1029/ 2003 GL019398.
Wessel, P., and W. H. F. Smith (1995), New version of the Generic Mapping Tools released, Eos Trans. AGU, 76, 329

W. L. Ellsworth, U.S. Geological Survey, Menlo Park, CA 94025, USA. K. Imanishi, Geological Survey of Japan, AIST, Tsukuba Central 7, 1-1 Higashi 1-Chrome, Tsukuba, Ibaraki 305-8567, Japan. (imani@ni.aist. go.jp)

S. G. Prejean, USGS Alaska Volcano Observatory, 4200 University Ave., Anchorage, AK 99508, USA. 